\title{
Extraction and characterization of natural dye from arils of Celastrus paniculatus Willd. for textile application
}

\author{
D.H. Tejavathi ${ }^{1 *}$ and R. Niranjan \\ Department of Botany, Bangalore University, Bangalore 560 056, India \\ *Corresponding author-tejavathi_hanu@yahoo.com
}

Available online at: www.isroset.org

Received: 05/Oct/2018, Accepted: 19/Oct/2018, Online: 31/Oct/2018

\begin{abstract}
Celastrus paniculatus Willd., is one of the important medicinal plants belongs to the family Celastraceae. The present study is carried out for the first time to extract natural pigment from the arils, which are of orange-red in colour. The dye was extracted with hot water boiling method. The color of the extracted dye is orange. However, the orange color changes to yellowish-orange on cotton fabric when dyed .The dye potential of the extract was evaluated by dyeing on cotton fabrics without/with mordants such as ammonium ferric sulphate, ferrous sulphate, and copper sulphate. Shades of yellow color were observed when different mordants were used. Ferrous sulphate and copper sulphate have exhibited good coordination complexes with dye molecules that have reflected in imparting bright yellow shades to the fabric. The dyed cotton fabric was tested for color fastness by light, rub and wash fastness. The fabric showed no significant changes in rub and light fastness. However, studies have showed slight fading in color when subjected to wash fastness. The spectroscopic characteristics were determined with the help of UV-Vis and FTIR. UV-Vis spectral analysis of both mordanted and unmordanted dye have revealed varied peaks for the pigments indicating different binding affinity of mordants with chromphore groups within the pigments that give different shades. Analysis of dye by Infrared spectroscopic study has displayed the presence of carotenoid content at $940 \mathrm{~cm}^{-1}$. The findings disclosed that the extraction of dye from aril of Celastrus paniculatus Willd. has promising prospect in textile industry.
\end{abstract}

Keywords: Aril, Celastrus paniculatus, Cotton fabric, Mordants, Natural dye, Spectral analysis.

\section{INTRODUCTION}

The use of natural dyes/colorants has decreased largely since the advent of synthetic dyes in 1856 by William Henry Perkin accidently [1]. Recently, dyes derived from natural sources have emerged as important alternatives to synthetics dyes, which have been reported to have carcinogenic effects. Natural dyes have better biodegradability and generally have higher compatibility with the environment. The natural dyes are clinically safer than their synthetic analogues in handling and use because of non-carcinogenic and biodegradable nature [2]. In India, more than 450 plants can yield dyes [3]. Archaeological evidences have shown that, particularly in India and the Middle East, dyeing is being carrying out since 5000 years. Generally, light fastness, wash fastness and rub fastness are important parameters to be considered for textile fibers. However, dyeing textile using natural dyes was found to yield poor color because of inadequate fastness properties [4]. Hence, mordants are being used to enhance the effectiveness of these characteristics to form a dye complex to fix the dye and fiber together. Metal ions of mordants act as electron acceptors for electrons donors to form co-ordination bonds with the dye molecule, making them insoluble in water [5]. Common mordants used for dyeing are ammonium ferric sulphate (alum), chrome, stannous chloride, copper sulphate and ferrous sulphate etc. [6]. In present study, color pigments were isolated from orange colored arils of Celastrus paniculatus and studied in order to understand the processtaking place during its usage in textile coloration along with/without mordants. In addition, the effect of mordants employed in the dyeing process has been studied. Further, Spectroscopic and FTIR analysis have been conducted to know the nature of compounds and for identification of certain bonding elements/ functional groups present in the dye.

This article deals with the research on extraction of dye from arils of C.paniculatus and dyeing of cotton fabric. The importance of natural dyes in place of synthetic dyes, significance of using mordants in textile industry and justification of the objectives are briefly explained in introduction. This section is followed by the materials and methodology, which briefly deals with plant collection, its authentication,design of experiments for the extraction of the dye and dying process. The results observed by our present 
experiments are depicted in tables, figures and supplemented with photographs. The present findings are discussed thoroughly by comparing our findings with previous relevant works. Finally, the feasibility of utilizing the orange dye from the arils of Celastrus paniculatus in cotton textile industries along with recommendations is mentioned in conclusion.

\section{MATERIALS AND METHODOLOGY}

\section{Materials}

Source: Healthy mature fruits were collected from the plants growing in the outskirts of Yellahanka and GKVK Agricultural University campus, Bangalore, Karnataka, India (Fig. 1A). The source plants were identified and authenticated by Southern Regional Center, Botanical Survey of India, Coimbatore, Tamil Nadu, India (BSI/SRC/5/23/2017/Tech/1598). Herbarium of the authenticated material is deposited in Department of Botany, Bangalore University, Bangalore, India (Voucher number: BUB 301).

Substrate: $100 \%$ cotton cloth was purchased from departmental stores, Bangalore, Karnataka.

Mordants: Ammonium ferric sulphate (Alum), Copper sulphate and Ferrous sulphate.

\section{Methods}

The dyeing of cotton fabric with aril dye extract was carried out in five stages - Preparation of raw material, extraction of dye from aril, scouring of cotton, mordanting and dyeing.

\section{Preparation of raw material}

Mature fruits were thoroughly washed in running tap water to remove impurities. They were then, cut open to collect the seeds. Orange colored arils were removed from the mature seeds and stored at $4^{\circ} \mathrm{c}$ in refrigerator for further studies (Fig.1B-1C).

\section{Extraction of colorant}

Customary boiling method was followed to extract the dye. $100 \mathrm{gm}$ of aril was weighed accurately and added to $500 \mathrm{ml}$ of distilled water in conical flask of capacity of $1 \mathrm{~L}$. The material was allowed to boil for 50-60min. The color was extracted from arils by the end of $60 \mathrm{~min}$. The solution was filtered to obtain crude orange dyestuff (Fig.1D).

\section{Scouring of cotton}

Cotton cloth chosen for the experiment was weighed and measured accurately before scouring. It is washed in a solution containing $0.5 \mathrm{~g} / \mathrm{L}$ of sodium carbonate and $2 \mathrm{~g} / \mathrm{L}$ of non-ionic detergent (Tween-20) at $50^{\circ} \mathrm{C}$ for $25 \mathrm{~min}$ and ratio was maintained at 1:40( $\mathrm{Na}_{2} \mathrm{Po}_{4}$ :Tween20). The scoured material is thoroughly washed in distilled water and dried at room temperature. Prior to mordanting and dyeing, the cotton fabric was soaked in clean water for 30min [7-10].

\section{Mordanting}

Scoured cotton cloth was treated with different metal salts/mordants like ammonium ferric sulphate, copper sulphate and ferrous sulphate. $2 \mathrm{~g}$ of above-mentioned mordants are mixed with $100 \mathrm{ml}$ of distilled water to make the concentration of $2 \%$.Thus; prepared mordants were mixed with water individually in the ratio of 1:40. The mordants were used either individually or in combinations. The wetted cotton sample was treated with different mordant solutions and then brought to heating. Temperature of water bath was raised to $70-80^{\circ} \mathrm{C}$ over a period of $30-40 \mathrm{~min}$ and left at that temperature for another $20-30 \mathrm{~min}$. The mordanted material was then rinsed with water thoroughly, squeezed and dried at room temperature[11].

\section{Dyeing}

Cotton fabric samples treated with/without mordants were dipped in aril extract directly and gently boiled for another $30 \mathrm{~min}$ at the temperature of $70-80^{\circ} \mathrm{C}$ on a hot plate. The $\mathrm{pH}$ was maintained at 4 by adding a sodium phosphate buffer solution. The scoured cotton cloth is kept inside dye solution for $30 \mathrm{~min}$ to $1 \mathrm{~h}$. After dyeing, the dyed material was washed with cold water and dried at room temperature.

\section{Fastness Tests}

The dried dyed cotton cloth was tested for light fastness, wash fastness and dry fastness. Light fastness was analyzed by exposing the dyed cloth to direct sunlight for $24 \mathrm{~h}$, for tenure of 3 days consecutively. The wash fastness was carried out by washing the dyed fabric with commonly used detergent $(1 \mathrm{~g} / \mathrm{l})$. The dyed fabric was rubbed to check the rub fastness for fading of color $[12,13]$.

\section{UV-Visible Spectroscopy and Fourier Transform Infrared Spectroscopy}

The absorption spectra of the dye were obtained using UVVis double beam Elico spectrophotometer at a wavelength ranging from $210 \mathrm{~nm}$ to $1200 \mathrm{~nm}$. The FTIR studies have been performed on a Perkin Elmer Spectrometer Spectrum -1000, in the wave length range of $400-4000 \mathrm{~cm}^{-1}$.

\section{RESULTS AND DISCUSSION}

Nature expresses itself in a wide spectrum of colors all around us. Natural dyes provide an environmentally safe option for coloring of food and other materials. Since the production of synthetic dyes is dependent on petrochemical sources that results in the production of carcinogenic amines, natural dyes play a major role in safety issues[14].Moreover, many countries have already imposed stringent environmental standards over these dyes. For instance, Germany has banned the azo dyes [15]. The objectives of this study were to extract natural dye from the aril of C.paniculatus; to test some commonly used mordants for their ability to fix color on cotton fabric and to characterize the dye by analyzing the spectra obtained by UV-Vis and FTIR. The dye extracted from the aril by boiling method was orange in color (Figure 1D). Baishya et al. [16] have followed the same method to obtain purple color dye from the flowers of bottlebrush.

Different shades of yellow and orange were obtained from the dye when the mordants were used in various concentrations and combinations. Alum, copper sulphate and 
ferrous sulphate were used as mordants in the present study. A ternary complex comprising fiber, mordant and dye is formed when mordant is used. Strong coordination tendency of $\mathrm{Fe}$ enhances the interaction between the fiber and dye resulting in high dye uptake [9]. However, bright yellow colour was seen when the fabric was treated with copper sulphate and ferrous sulphate (Fig.1E-1F). Better color strength results are dependent on the metal salt used [17]. Ferrous sulphate and copper sulphate have the ability of forming co-ordination complexes that gives high resistance to fading. The presence of hydroxyl or carbonyl groups in dye structure is capable to form metal complex with the positively charged metals. In addition one molecule of dye can form a bond with one site of fiber molecule, while one molecule of mordant can form bonds with 2 or more molecules of dyes $[18,19]$.The yellow shades thus obtained from single dye using different mordants like alum, ferrous sulphate and copper sulphate, may be due to varied interaction of mordant salts and bonding with dye molecules. Similar results were obtained when the dye from the flowers of Tecoma stans and bottlebrush were treated with various mordants $[16,20]$. Uddin[21] has concluded that the color values were found to be influenced by the mordants from his study on silk dyeing with natural dye from mango leaves.

Mordanted cotton cloth was immediately used for dyeing because some mordants are photosensitive. In the present investigation, all mordants have shown comparatively good shades of color yield. Colour fastness of the fabric depends on the high dye uptake and interaction between the dye and the fabric through the type of the mordant used. The mordanted fabric dyed with the aril dye in the present study has showed good rub fastness and light fastness as well. However, color slightly fades when subjected to wash fastness; this may be due to the presence of metal ions in soap water. Wash fastness of the dye depends on the rate of diffusion and accumulation of the dye inside the fabric [22]. Nevertheless, Jyothi[9] has observed the changes in color of the fabric treated with African marigold flower dye when it was washed with soap. The changes in color were attributed to the usage of alkaline washing. Color shade changes of the dye obtained from tamarind seeds were also depends on the changes in washing conditions and the result of sensitivity of the dye molecule to detergent solution [23]. The drastic color changes were observed when the cotton fabric dyed with mangrove bark extract was subjected to wash fastness test [ 5].That was ascribed to the ionization of the hydroxyl groups in the dye molecules under alkaline condition of the standard detergent or decomposition of the dye itself. However, improvement in light fastness when mordants are used is may be due to the formation of complex with transition metal. Thus, formed complex protects the chromophore from photolytic degradation.

UV-Vis spectroscopy is used to identify the colorant/dye by its peaks at predominating wavelength indicating the colors. Natural dyes present in plants are pigmentary molecules, which impart color to the materials.
Normally for all the natural dyes, the spectra specially indicate different peaks for mixed colorants available in their extract in both UV and visible region. Absorption at maximum wavelength for aqueous unmordanted orange dye extract showed at $435 \mathrm{~nm}$ for chl'a' and $455 \mathrm{~nm}$ for chl'b', $510 \mathrm{~nm}$ for carotenoids and 480nm for xanthophylls in the present investigation. Further cotton fabric treated with different mordants produced shades of yellow due to varied interaction between the dye and mordants. The aqueous extract of the dye treated with different mordants results in significant change in the absorption spectra with chl a, chl b, carotenoid and xanthophyll pigments at varied peaks (Table 1). Spectral analysis showed different binding affinity of mordants with chromphore groups within the pigments that give different shades. Similar results were obtained by Ghurde et al.[23] who have analyzed the dye obtained from flowers of Ixora coccinea by spectroscopic studies using various extracts with different concentrations of mordants.

FTIR spectroscopy is a vibrational spectroscopic technique that can be used to optically probe the molecular changes associated with tissues. Spectral bands in vibration spectra are molecule specific and provide direct information about the biochemical composition. FTIR peaks are relatively narrow and in many instances, it can be associated with the vibration of a particular chemical bond. FTIR spectroscopy has become a well-accepted and widely used method to characterize biological tissues. The technique of FTIR spectroscopy has become a technique of choice for scientists who are interested in analyzing the chemical structural properties of natural and synthetic tissues. FTIR was conducted to study few biochemical compounds necessary for pigments. The extracted dye in the present study is recorded in the wavelength ranging from $4000-400 \mathrm{~cm}^{-1}$.An FTIR spectrum has revealed the characteristics of some organic compounds. Fatty acids and saccharides peaks are elevated at 892 $\mathrm{cm}^{-1}$. Whereas carotenoid contents are manifested at 940 $\mathrm{cm}^{-1}$. The lipid contents were visualized at peak frequencies of 2956 and $2874 \mathrm{~cm}^{-1}$ (Fig.2). The cotton fabric with or without dye used in the present study was also subjected to FTIR analysis which correlates with the FTIR spectra of aril (Fig.3). The graph clearly indicates the binding of carotenoid and lipids with cotton fabric, when it is dyed. Characterization of dye obtained from the leaves of Justicia spicigera-using FTIR has revealed the presence of anthocyanin groups [24].The previously mentioned data indicates the potentiality of the orange dye obtained from the aril of C.paniculatus with/without mordant in cotton dyeing industry. Cotton fabric samples mordanted with different combinations of alum, ferrous sulphate and copper sulphate have shown various shades of yellow and orange. The dyed fabric has withstood the rub and light fastness tests significantly. The spectroscopic studies from UV-Vis and FTIR have indicated the presence of carotenoid pigments that imparts orange to yellowish orange color to the dye. 


\section{CONCLUSION}

The previously mentioned data indicates the potentiality of the orange dye obtained from the aril of C.paniculatus with/without mordant in cotton dyeing industry. Cotton fabric samples mordanted with different combinations of alum, ferrous sulphate and copper sulphate have shown various shades of yellow and orange. The dyed fabric has withstood the rub and light fastness tests significantly. The spectroscopic studies from UV-Vis and FTIR have indicated the presence of carotenoid pigments that imparts orange to yellowish orange color to the dye. Thus, based on the results, it can be concluded that the dye obtained from the arils of Celastrus panicluatus has good scope for application on cotton fabrics. Further, this dye needs to be explored in food industry for safety use.

\section{ACKNOWLEDGMENT}

Thanks are due to UGC, New Delhi for granting BSR-Faculty fellowship for one of the author (DHT). The present work was carried out under this fellowship.

\section{REFERENCES}

[1] I. Holme, "Sir William Henry Perkin: a review of his life, work and legacy", Color, Technology .Vol.122, pp. 235-251, 2006.

[2] A. Haji, "Functional dyeing of wool with natural dye extracted from Berberis vulgaris wood and Rumex hymenosepolus root as biomordant", Iran Journal of Chemistry and Chemical Engineering, Vol.29, Issue.3, pp.55-56, 2010.

[3] R. Siva, "Status of Natural dyes and dye yielding plants in India", Current Science, Vol 92, Issue.7, pp.916-924, 2007.

[4] K. Sachan, V.P. Kapoor, "Optimization of extraction and dyeing conditions for traditional turmeric dye", Indian Journal of Traditional Knowledge, Vol.6, Issue.2, pp.270-278, 2007.

[5] R. Mongkholrattanasit, N. Punrattanasin, N. Rungruangkitkrai, B. Somboon, N. Narumol, M. Nakpathom, "Dyeing, fastness and UV protection properties cotton fabric dyed with mangrove bark extract”, Cellulose Chemistry and technology,Vol.50, Issue.1, pp.163-171, 2016.

[6] S.S. Kulkarni, A.V. Gokhale, U.M. Bodake, G.R. Pathade, "Cotton dyeing with natural dye extracted from pomegranate (Punica granatum) Peel", Universal Journal of Environment research and technology Vol.1, Issue.2, pp.135-139, 2011.

[7] M.A. Salam, "Study of color fastness properties onto bleached sulphonated jutecotton blended fabrics with basic dyes", Journal of Textile and Application and Technology Management, Vol.4, Issue.4, pp.1-6. 2005.

[8] N. Pruthi, G. Chawla, S. Yadav, "Dyeing of silk with Barberry bark dye using mordant combination", Natural Product Radiance, Vol.7, Issue.1, pp.40-44, 2008.

[9] D. Jothi, "Extraction of Natural dyes from African marigold flower (Tagates erecta) for Textile coloration", Autex Research Journal, Vol.8, Issue.2, pp.49-53, 2008.
[10] P.S. Vankar, R. Shanker, S. Wijayapala, "Dyeing cotton silk and wool yarn with extract of Garnicia mangostana pericarp", Journal of Textile and Application and Technology Management. Vol.6, Issue.1, pp.1-10, 2009.

[11] C. Suitcharit, F. Awae, W. Sengmama, K. Srikulkit, "Effect of chitosans molecular weights on mangosteen dye fixation on cotton fabric", Journal of Mineral metals and material Society. Vol.20, Issue.1, pp.27-31, 2010.

[12] D. Raja, A. Arputharaj, C. Prakash, B. Ramesh, C.V.Koushik, "Study on dyeing behavior of cotton/Organic cotton knitted fabrics", Indian Journal of science and Technology, Vol.3, Issue.7, pp.746- 751,2010.

[13] P. Mishra, V. Patni, "Extraction and application of dye extracted from Eriophyid leaf galls of Quercus leucotrichophora-A, Himalayan Bluejack Oak", African journal of biochemistry research,Vol.5,Issue.30, pp.90-94, 2011.

[14] K. Hunger, Industrial dyes. Darmstadt: WILEY-VCH Verlag GmbH \& Co.KGaA, 2003.

[15] M.A. Ali, H.A. Almahy, A.A. Band Ali, "Extraction of carotenoids as natural dyes from the Daucus carota Linn (carrot) using ultrasound in Kingdom of Saudi Arabia", Research journal of chemical sciences, Vol.3, Issue.1, pp.63-66, 2013.

[16] D. Baishya, J. Talukdar, S. Sandhya, "Cotton Dying with Natural Dye Extracted from Flower of Bottlebrush (Callistemon citrinus)", Universal journal of Environmental Research and Technology, Vol. 2, Issue.5, pp.377-382, 2012.

[17] M.M. Kamel, H.M. Helmy, N.S. Hawary, "Some studies on dyeing properties of cotton fabrics with Crocus sativus (saffron) flower using an ultra-sonic method". Autex Research Journal. Vol. 1, pp.29-35, 2009.

[18] M.G. Uddin,"Effects of different mordants on silk fabric dyed with onion outer skin extracts" Journal of textile and research, pp.1-8, 2014.

[19] P.Temani, D.B. Shakyawar, L. Ammayappan, V. Goyal, S.A.Wani, "Standardization of dyeing condition of cochineal extract on pashmina yarn", Journal of Textile Association Vol.72, Issue.2, pp.90-92, 2011.

[20] S. Chandra Mohan, S. Thiripura Salini, R. Senthil Kumar, A. Thiyagarajan, "Dyeing of cotton with natural dyes obtained from flower of Tecoma stans", Universal Journal of Environmental Research and Technology, Vol.2, Issue.1, pp.41-46, 2012.

[21] M.G. Uddin, "Extraction of eco-friendly natural dyes from mango leaves and their application on silk fabric", Textile for Cloth and Sustainability, Vol.1, Issue7, pp.1-8, 2015.

[22] M. U. Ghurde, M. M. Padwad, V. R. Deshmukh, and S. N. Malode, "Extraction of Natural Dye from Ixora coccinea (Linn.) Flowers for Cotton Fabric Colouration", International journal of science and research, Vol.5, Issue.1, pp.1272-1276, 2016.

[23] S. Tepparin, P. Sae-be, J.Suesat, S. Chumrum, W. Hongmeng, "Dyeing of cotton, Bombyx mori and eri silk fabrics with the natural dye extracted from tamarin seed", International Journal of Bioscience, Biochemistry and Bioinformatics Vol.2, Issue.3, pp.159-163. 2012.

[24] Y. Espinosa-Morales, J. Reyes, B. Hermosin, J.A. Azamar-Barrios, "Charcterization of a natural dye by spectroscopic and chromatographic techniques", Mater. Res. Soc. Symp. Materials Research society symposia proceedings.Vol.1374, pp.1-12,2012. 

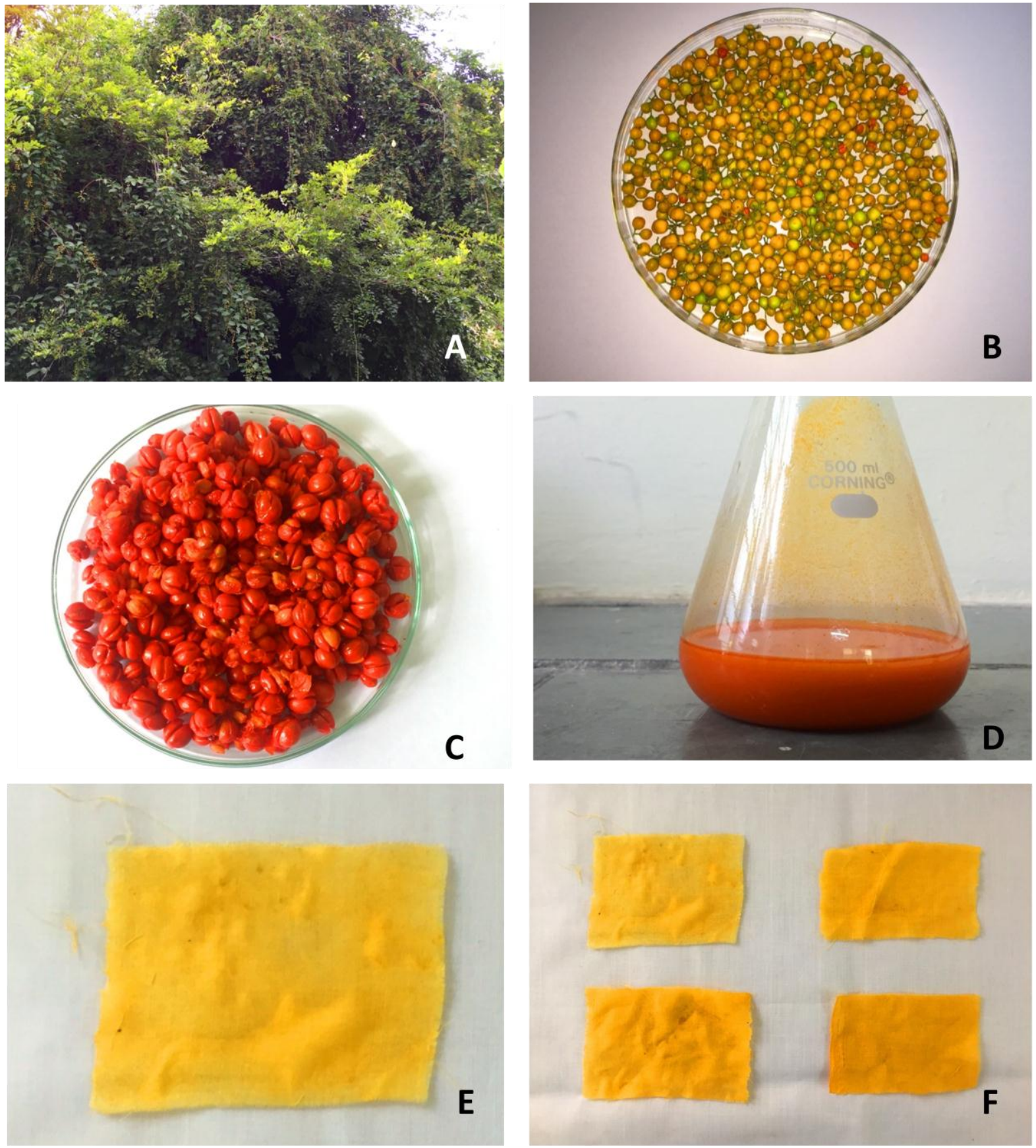

Fig. 1 : A- Woody liana, B - Tricarpellary fruit, C- Aril covering seeds, D- Extracted dye, E- Fabric dyed without mordants, F- Fabric dyed with mordants:

(N- Normal, A- Alum, F- Ferrous sulphate, C- Copper sulphate) 


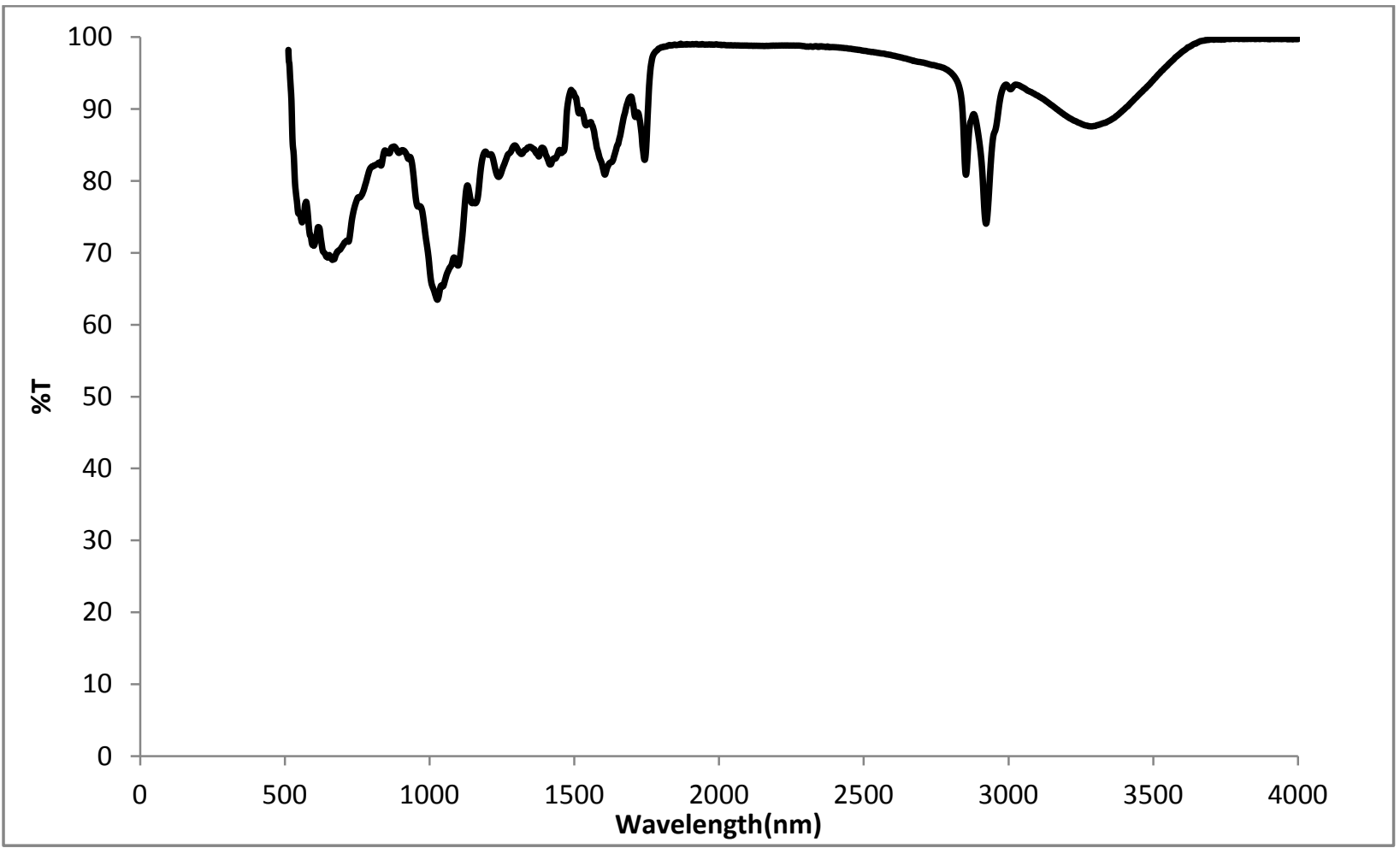

Figure 2- FTIR of Aril

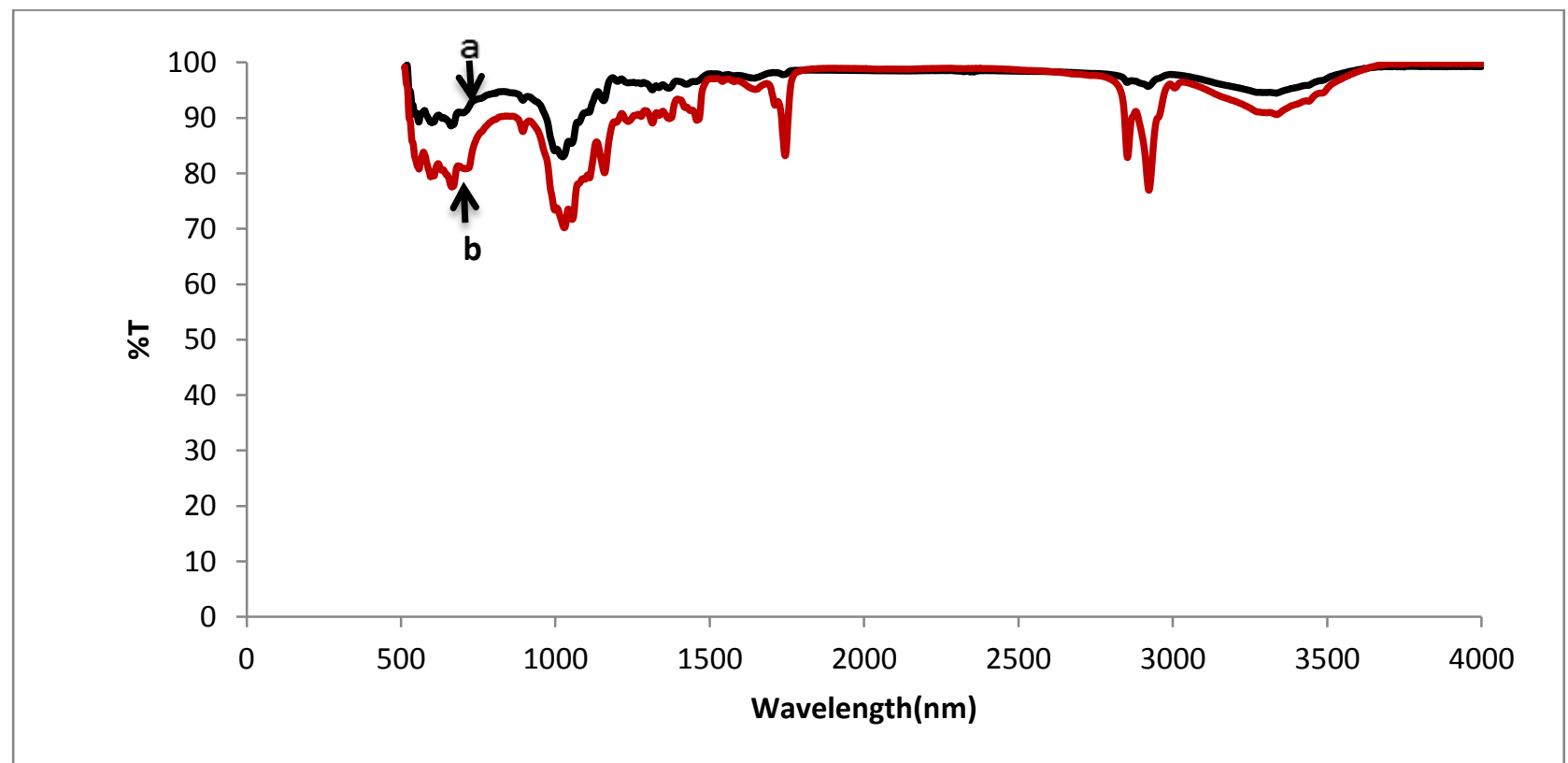

Figure 3: FTIR spectra of Cotton fabric with and without dye. a-Without dye

b-With dye 
Table 1- UV-Vis absorption spectrum of aqueous extracted dye pigment from aril of Celastrus paniculatus Willd and its interaction with different mordants.

\begin{tabular}{|c|c|c|c|c|}
\hline \multirow{2}{*}{ Pigments } & \multirow{2}{*}{$\begin{array}{c}\text { Wavelength } \\
\text { Without Mordant } \\
\text { (nm) }\end{array}$} & \multicolumn{3}{|c|}{ Mordants } \\
\hline & & Alum & $\mathrm{FeSO}_{4}$ & $\mathrm{CuSO}_{4}$ \\
\hline Chl a & 435 & 435 & 435 & 435 \\
\hline Chl b & 455 & 580 & 582 & 586 \\
\hline Carotenoids & 580 & 510 & 512 & 510 \\
\hline Xanthophyll & 480 & 480 & 480 & 480 \\
\hline
\end{tabular}

\section{Author's Profile}

DR.D.H.TEJAVATHI, Professor (Retd.) of Botany, Bangalore University, Bangalore, India. She was a BSR Faculty Fellow in the department of botany, Bangalore University during the period 2014-2017. She has published 93 research articles in various national and international journals and completed 8 research projects funded by DST, CSIR, BU-UGC and MoEFCC, India. She has successfully guided 22 research students for Ph.D degree and 15 students for M.Phil degree. She was conferred with an award 'Merit of Excellence' for outstanding contribution to the Medicinal plant research during the $4^{\text {th }}$ international conference on Medicinal plants and herbal products held at John Hopkins University, Rockville, M.D, USA,2012. She is a recipient of Lifetime Achievement Award for outstanding contribution in Medicinal Plant Research at IJTA $4^{\text {th }}$ International Conference on Recent Advances in Agriculture and Horticulture Science held at Jodhpur, India, 2016.

Mr. R. NIRANJAN has completed M.Sc.in Botany from Bangalore University, Bangalore,India, securing First rank. Currently pursuing $\mathrm{PhD}$ degree under the guidance of Dr.D.H.Tejavathi and working on Tissue culture in medicinal plants and synthesis of nanoparticles. He has published two papers in UGC recognized international journals. He has attended

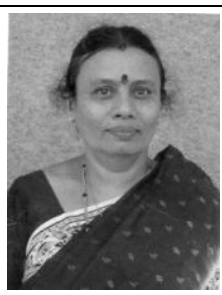
National and International conferences and a recipient of Best oral and poster presentation awards. 